\title{
A Probe into the EFL Learning Style Preferences of Minority College Students: An Empirical Study of Tujia EFL Learners in Jishou University*
}

\author{
Feng Liu \\ Faculty of English, College of Literature and Law, Sichuan Agricultural University, Ya'an, China \\ Email: liufeng_5150@126.com
}

\begin{abstract}
The purpose of this study is to find out the learning style preferences of Tujia EFL learners in Tujia-Miao Autonomous Prefecture of Xiangxi ${ }^{1}$ and provide some suggestions for improving effectiveness of College English teaching in Tujia-Miao Autonomous Prefecture of Xiangxi based on the findings. The findings of the study have both theoretical and practical significance. Theoretically, first, the feasibility of the multidimensional questionnaire of learning styles is proved in this empirical study. At the same time, the successful application of the multidimensional learning-styles instrument will help researchers to draw a complete picture of students' learning style preferences. Second, the present study also found "the ethnic culture and socialization are the most important factors that influence the Tujia EFL learning style preferences". Practically, the results help the Tujia EFL learners understand their own learning style preferences and instructors in making decisions about course design and improving the methods of the Tujia EFL classroom teaching. Methodologically, the successful application of both quantitative and qualitative approach and the use of a multidimensional learning-styles instrument expand the methodology of learning styles research.
\end{abstract}

Index Terms - Tujia EFL learners, learning style preferences, ethnic culture, socialization

\section{INTRODUCTION}

There has been a prominent shift from teaching to learning in the field of second language acquisition for past few decades in Western countries. A large number of studies have shown individual differences play an important role in second language acquisition.Learning styles is one of the most variables influencing performance in second language acquisition (Oxford, Lavine, Crookall, 1989). In addition, learning styles was found to be related to the choice of learning strategies (Oxford, 1990). The field of learning styles in both complicated and fragmented. Different researchers have investigated the different aspects of learning styles. According to Dunn, Germake, Jalali and Zenhausern (1989), they found at least 21 components have been identified, but probably most individual have only 6 to 14 strongly preferred styles.

The present study has been divided into two parts: The first is for the distribution of typical patterns of learning styles in Tujia EFL learners. The second step is to help the instructors in making decisions about course design and methods of Tujia EFL classroom teaching base on the results of first step

\section{Literature PREVIEW}

\section{A. Definitions of Learning Styles}

In reference to the definition of learning styles, many researchers have made endeavors from different perspectives based on the different rationales: 1) Gregorc (1979) defined Learning style as "Teachers's teaching styles and learners' learning styles are virtually their own disposal of matters"(p.236) 2) Keefe (1979) assumed that learning style is "The composite of characteristic cognitive, affective, and physiological factors that serve as relatively stable indicators of how learners perceive, interact with, and respond to the learning environment."(p.2) 3) Schmeck (1983) viewed learning style as a certain kind of method or strategy. Everybody's learning methods come from some particular strategies, which indicate his/her learning styles; 4) Scarcella (1990) defined learning style as "cognitive and interactional patterns which affect the ways students perceive, remember and think;(p.12) 5) the definition of Oxford (1990) is "The general approaches students use to learn a new subject or tackle a new problem or overall patterns that give general direction to learning behavior"(p.34).

Some similarities can be inferred from these definitions though they are different in expressions: First, learning style

\footnotetext{
* The research is supported by the "Foundation of Sichuan Agricultural University". Grant Number : SICAU06170930

1 "Tujia EFL learners" is a group of students with Tujia nationality which is one of the 55 minority groups in China. "Tujia-Miao Autonomous Prefecture of Xiangxi" locates in the western region of Hunan Province in China, in where a large number of Tujia and Miao students live and study.
} 
is the general tendency in every individual's learning process and it is the biological characteristics involving cognitive, affective, and psychological traits of an individual. Second, learning style is unique to each individual because the differences in cultural background and learning experience. Third, learning style is relatively stable and it seldom changes with environment.

\section{B. Reid's Classification of Learning Styles}

Reid (2002) divided learning styles into three categories: cognitive learning styles, sensory learning styles and affective/personality learning styles. The present study is in favor of Reid's classification.

1. Cognitive learning styles

Field-independent/Field-dependent

This is the most famous pairs of learning styles. Field-independent learners prefer a learning style that relies on the internal frame of reference; they are analytic and perceive a field in terms of its component parts; and they are not so sociable or skilled in interpersonal relationship. Field-dependent learners prefer a learning style that relies on the external frame of reference: they are holistic and perceive a field as a whole, and they are socially sensitive, with good skills in interpersonal relationship. (Ding, 2004)

Reflective/Impulsive

Reflective learners learn more effectively when they come to consider options before responding (they are accurate language learners). Impulsive learners learn more effectively when they are able to respond immediately and to take risks (they are fluent language learners).

2. Sensory Learning Styles

Perceptual Learning Styles

Perceptual learning styles demonstrate the physical, perceptual ways of learning. These can be subdivided into visual, auditory, kinesthetic, tactile, and haptic modality. Visual learners prefer learning through seeing. Auditory learners prefer learning through hearing. Tactile learners prefer learning through touching. Kinesthetic learners prefer learning through whole-body movement. Haptic is consisting of tactile and kinesthetic in some studies, the haptic learners prefer learning through touching and whole-body movement.

3. Affective/Temperament Learning Styles

Tolerance/Intolerance of Ambiguity

Ambiguity tolerance learners are "open-minded" in accepting contradictory propositions. They prefer learning through conducting experiments and taking risks. Ambiguity intolerance learners are "close-minded" in rejecting contradictory propositions. Therefore, they prefer learning in less flexible, less risky and more structured situations.

\section{Methodology}

\section{A. Subjects}

The study involved 146 Tujia freshmen (75 males and 71 males) from Jishou University*, with their age ranging from 18 to 22. Another 4 teachers and 60 Tujia students from English Department also participate in the pre-test for instrument remedy.

\section{B. Instruments}

The study employed a self-reported multi-dimensional questionnaire adapted from one that had been designed by researchers for the study of students' learning style preferences in Xi'an Jiaotong University (Liu\&Dai, 2003).Their learning styles questionnaire have been developed by incorporating some previously affirmed instruments which have relatively higher reliability and validity.

The interviews invited 10 students to be randomly selected from subjects and 4 teachers teaching the 10 students.

\section{Data Collection}

To ensure reliability, one pre-test were carried out before the questionnaire was administrated to the subjects.

The pre-test was conducted first by using the original questionnaire. Sixty Tujia students from English Department of Jishou University. They are encouraged to make some comments on questionnaire.

The modified questionnaire was administered to 165 Tujia students and all the subjects were instructed on how to fill out the questionnaire. The questionnaires should be finished in 30 minutes. It took 7 days to conduct the data collection and a total of 165 questionnaires were returned to the researcher. After a careful examination, nineteen questionnaires were excluded because the results having successive similar choices. After the questionnaire survey, the interviews for teachers and students were conducted and the whole process of interviews were recorded and reserved for analysis.

\section{Data Analysis}

Based on the results of questionnaire, the mean and frequency distribution of the sample are presented to show the overall tendency of the learning style preferences of Tujia students. The record of the interviews were used as supplementary. 


\section{RESULTS AND DiSCUSSION}

Based on the analysis of the collected questionnaire data, a detailed discussion related to the distribution of learning styles of Tujia EFL learners raised earlier will be presented:

TABLE 1.

MEAN AND DEVIATION OF LEARNING STYLE VARIABLES

\begin{tabular}{lcc}
\hline Variables & Mean & SD \\
\hline Visual & 16.11 & 3.152 \\
Auditory & 14.57 & 2.789 \\
Hand-on & 17.19 & 2.391 \\
Independent & 17.23 & 2.950 \\
Dependent & 15.17 & 3.452 \\
Group-oriented & 15.08 & 3.922 \\
Individual-oriented & 17.82 & 3.212 \\
Analytical & 14.42 & 3.025 \\
Holist & 15.33 & 2.752 \\
Serialist & 16.79 & 3.468 \\
Random & 14.96 & 2.291 \\
Impulsive & 14.24 & 2.798 \\
Reflective & 18.09 & 3.150 \\
\hline
\end{tabular}

\section{Frequency Distribution of Learning Styles}

Table .1 showed the mean and standard deviation of each learning style. It indicated clearly the general distribution of learning styles of Tujia students. Five of them are strongly preferred by Tujia students: Reflective, individual-oriented, independent, hand-on and serialist. Table 3.1 also showed that the least preferred learning styles are impulsive (Mean=14.24) and Analytical (Mean=14.42). The values of standard deviation showed the biggest differences can be found in group-oriented $(\mathrm{SD}=3.922)$ and smallest is random style $(\mathrm{SD}=2.291)$.

1. Tendency 1: Reflective

According to table 4.1, the mean score $(\mathrm{M}=18.09)$ of reflective was the highest among all the other learning styles and higher than the average score of 15 , which suggested the No.1 learning style of Tujia students is reflective. The noticeable tendency indicates that most Tujia students preferred a reflective style.

Reid (2002) pointed out that reflective learners learn more effectively when they come to consider options before responding (they are accurate language learners). From Reid's definition, the Tujia EFL learners are accurate language learners. The finding of the current study is consistent with the image of Tujia students. There are two ways to explain the results:

First, owing to some historical and geographical reasons, the English education in Xiangxi is lagging and some of the Tujia EFL learners are in lower English proficiency, so they seldom speak in class or they need longer time to prepare before they answer the teachers' questions. In addition, for most of the Tujia students, English is their third language, compared to Han EFL students, they have to overcome more difficulties in learning English.

Second, according to Reid's explanation: Individuals are most likely not born with a genetic predisposition to learn analytically or relationally, visually or kinesthetically. They "learn how to learn" through the socialization process that occur in families and friendship groups (2002). Self-dignity is highly valued in Tujia culture. In Tujia society, people are afraid of losing face in the public. At the same time, Chinese people have been greatly influenced by the Confucian tradition. Under the influence of Chinese culture and Tujia culture, the Tujia students possess stronger self-esteem than Han students.

2. Tendency 2: Individual-Oriented

Based on the Table.1, the mean score of Individual-oriented indicates that some Tujia students preferred to learn individually.

Liu Ruiqing \& Dai Manchun (2003) pointed out that the individual-oriented dimension is in accordance with Oxford and Myers' introvert dimensions. That is to say, Tujia EFL learners are introvert. The result is different from the author's anticipation. On the surface, the Tujia students are straightforward, passionate and outgoing; they tend to gather together for living and learning. The preference for individual-oriented style might be attributed to the following reasons.

First, the ethnic culture plays an important role in shaping their learning styles. Because self-design and self-choice are highly valued in traditional Tujia culture, they like to make decisions by themselves. The second possible reason is Tujia EFL learners' living conditions. Tujia-Miao Autonomous Prefecture of Xiangxi is a remote area located in Western Hunan province. Tujia students have fewer opportunities to be in touch with the latest information and they also have fewer ways to cultivate themselves than Han students. To most Tujia students, the one and only goal is to take different kinds of examinations and to get higher diploma. Therefore, they do not want to participate in other activities in University and they choose to study by themselves. Although the admission of University for them is comparatively low, they also have to work hard. They are faced with competitions from Han students after they enter the University, which calls for long time of hard works by themselves.

3. Tendency 3: Independent

The independent style (Mean=17.23) is the third preferred learning styles. The independent/dependent dimension 
derived from Willing's personality dimension of active/passive (Liu \& Dai,2003). According to the Liu \& Dai(2003), the Tujia EFL learners are active learners. The result is different from what can be found in the teachers' interview. In some teachers' eyes, Tujia students are passive English learners. Due to their lower English proficiency, Tujia students are always waiting for the ready answers from teachers and peers instead of thinking independently. But the finding reveals that Tujia students prefer to make decisions by themselves in English learning classroom. They make plans for their own learning actively instead of following the teachers' instructions passively.

Based on the finding, it may be safe to say that learning styles are also determined by social, cultural and environmental factors coming from outside. The underlying reasons of the preference of independent style lie in the environment the Tujia students live in .Tujia-Miao Autonomous Prefecture of Xiangxi is a mountain area with inconvenient transportation. The tough living environment nurtures a spirit of independence and self-reliance. Another explanation might be the construction of Tujia families. An average Tujia family consists of 4 or 5 persons, including at least 2 children. Some families with agriculture background even have three or four children. Parents have little time to take care of every child in order to make a living. Therefore, the children have to live independently as early as possible, when they grow up, they have got used to be independent.

4. Tendency 4: Hand-on

As demonstrated in Table.1, the hand-on style is the forth preference of Tujia students. (Mean=17.19) The result is closer to the Reid's studies. Reid (1987) studied 1234 ESL learners in the intensive English language program in the U.S. The research showed that the hand-on style is the major learning style of Han students. Rossi-Le's (1989) study strongly demonstrated the hand-on style in both child and adult language learners. They all involve some movement in their language learning. In this sense, it can be concluded that Tujia students and Han students preferred to learn through participating in classroom activities.

As previous findings indicated, the learning styles can be determined by environment. The result is consistent with the author's anticipation. The special living environment of Tujia people in Xiangxi has an impact on the formation of learning style preferences of Tujia students. It is known that Tujia people in Xiangxi live in a relatively small region surrounded by high mountains and rivers. It is very common for one to tramp over hill and dale in order to move from one place to another. Living in such a harsh environment, Tujia students require movement and frequent break in activity. They like physical activities, games and role plays that let them get out of their chairs and move around. Since the hand-on style is also the major learning style of Han students, it is necessary for researchers to conduct researches about hand-on style such as the comparison of hand-on style between Han students and Tujia students or students from other ethnic groups.

5. Tendency 5: Serialist

Serialist is the fifth learning style of Tujia students. (Mean=16.79) Gregorc (1979) defined serialist as "Learners work their way through material sequentially and systematically"(p.236). That is to say, serialist learners will read books sequentially and systematically. Due to the inconvenient transportation and underdevelopment of economy and education in Xiangxi, it is difficult for Tujia English learners to obtain a wider perspective by processing a large number of materials. They just can obtain limited materials from teacher's recommendation. Once they get these materials, they will work their way through these materials sequentially and systematically. Because serialist and random styles are perhaps the least studied in learning styles research, the reason given by the present research may not complete and the future researches of the same kind are needed.

Apart from the five preferred learning styles, Tujia students also preferred a variety of other learning styles with means around 15. This result is the same as the findings of Wang Chuming (1992) on the study of Han students. EFL learning is so complex activity that one can not learn English well by resorting to one or two learning styles.

Another trend in the learning styles of Tujia students is worth our attention. Analytical style was regarded as negligible (Mean=14.42). According to Reid (2002), analytical learners learn more effectively by themselves and prefer setting their own goals, and responding to a sequential, linear, step-by-step presentation of materials. This finding suggested the traditional English teaching method was not welcomed by Tujia students, such as grammar-translation. But some English teachers in Jishou University always spend most of the time on single word and sentence, focus on some details instead of the context and the meaningful whole, and then the customary teaching styles of these teachers would be inefficient.

Generally speaking, the learning styles of reflective, individual-oriented, independent, hand-on and serialist are the five strongest learning style preferences in Tujia students. Teachers should take these styles preferences into consideration in English classroom.

\section{SugGeStions FOR InSTRUCTION}

All the information generated about learning styles will be of little use to us as ESL instructors unless we can somehow apply it to the classroom and our way of teaching (Reid, 2002). The followings are to examine some fundamental components of Tujia students' learning styles, then make practical suggestions for improving teaching effectiveness and trying to change the present embarrassing situation of English teaching in Jishou University.

A. Developing Self-awareness of the Learning Styles 
While it is essential that teachers in Tujia region have a practical understanding of learning styles, it is equally important for Tujia students to understand their own learning styles and to become aware of the strategies they avoid or seldom use. A Knowledge of one's own learning style is fundamental in "learning to learn" (Kinsella, 1994, p.25). Tujia students can not be expected to acquire successful language acquisition strategies, study methods, or collaborative learning skills incidentally, yet many come to EFL and other classes without a full realization of what is expected of them. Most of the Tujia students continue to use inappropriate approaches, with no awareness of the limitations of their habitual style of learning or more productive options for completing academic tasks. When teachers help Tujia students discover their own learning preferences, and then provide constructive feedback about the characteristic advantages and drawbacks, it is possible to help Tujia students develop a more versatile approach to learning, not just in the EFL classroom but also in every subject across the curriculum and in many situations beyond school.

\section{B. Linking Learning Styles and Learning Strategies in the EFL Classroom}

Because learning styles and learning strategies seem to be linked, it is important to create EFL courses that incorporate style and strategy training. Often students who become aware of their learning style preferences do not develop a parallel awareness of the strategies that they use naturally to assist them in learning the new language (Laura Rossi-Le, 1989). Therefore, in addition to help students find out their own learning styles, teachers should train students to use a variety of strategies that match their learning styles.

1. Reflective versus Impulsive

According to the study, reflective learning style is the major style of Tujia students while impulsive style is negligible. The dimensions of impulsive versus reflective becomes important in Tujia EFL classroom. It is very common to see most of the teachers want Tujia students to participate orally in EFL classroom. At times the teacher's goal may be for students to talk; it does not much matter what they say because the value is in the talking. At other times the teacher may be looking for particular responses, but if students come up with partial responses, the teacher is satisfied. But these kinds of discussions are difficult for the reflective Tujia students who need more time to get the right answer. Teachers should notice the Tujia students' learning style and try to improve their class design. They can organize classroom activities to give reflective Tujia students more time to think about the responses. For example, in reading classes, instead of moving from the reading of a text to the discussion of a text, teachers can first ask students to write down answers to questions. Teachers need to give reflective Tujia students enough time to write their answers. If the teacher wants Tujia students to talk about what they have written, it is better, for most Tujia students, to call on by name rather than to issue an open invitation to the class and expect someone to volunteer a response. But for some Tujia students from English Department, under the influence of western culture, they are impulsive learners, so the teachers should organize some activities for students to express themselves, such as public debate or discussions.

2. Analytical (Field-independent) versus Relational (Field-dependent)

The analytical/relational styles construct can offer teachers valuable implications for curriculum design and methodology in Tujia ESL classroom. The results of present study showed that analytical style is selected as a negligible style by most Tujia students. But some traditional teachers in Tujia ESL classroom are already tailored for the highly verbal and analytical learner. Therefore, some classroom activities should be improved; here are some useful strategies:

Display expressions of warmth and approval as well as confidence in every student's ability to succeed.

Make teachers reasonably available for study group assistance.

In addition to traditional grade rewards, provide social rewards that strengthen teachers' rapport with students.

Clarify the performance objectives of all lessons and tasks, and relate them to prior lessons.

Provide Tujia students with models that can serve as guidelines for successful completion of task demands. For example, distribute students' right answers or well-taken class notes to the whole class, then discuss why they are effective. The examples from their classmates may more elicit positive results from Tujia students than a written list of rules.

Organize more pair works or group works.

Create the opportunities for Tujia students to put their knowledge into practice.

3. Hand-on Style

Hand-on style is on the fourth place of Tujia students learning style preferences in terms of the present study. But the pen-and-paper teaching method in Tujia EFL classroom refrain Tujia student from their preferences. Therefore, a more communicative method should be employed. Suggested strategies include:

Real-time Interaction: Students might be encouraged to interact with classmates in realistic contexts. Teacher can also organize the activity of role-playing, such as the context of job hunting, shopping.

Contact with Native Speakers: Teachers can invite some native speakers from English-speaking countries to communicate with students.

Making use of multimedia systems: Fingers on the keyboard seem to have a different impact than pen/pencil on paper, and hand-on students respond well to this medium (Reid,2002). The computer use has been advantageous for the "hand-on' students. So the teachings can be moved to the multimedia-room, students are allowed to search relevant information and present what they have found on the screen.

4. Serialist

It is important for teachers to realize the serialist style of Tujia students. In addition to the textbooks, most Tujia 
students have no ideas about relevant materials of their English learning. They will read the materials sequentially and systematically when teachers made recommendations. So teachers should make every effort to introduce some useful books so as to make students' effort worthwhile.

\section{SUGGeStions FOR Future RESEARCH}

The findings and weaknesses of this study indicate some suggestions for future research:

First, in order to have a more extensive knowledge of Tujia students' learning style preferences, the future studies should invite the Tujia students from larger range such as Tujia EFL students from other regions in China.

Second, the future studies can make some modifications of instruments to avoid the shortcomings of this study. Moreover, the learning styles preferences in different grades can be studied. Last but not least, relationship between students' learning styles and academic successes can be investigated in the future researches.

\section{REFERENCES}

[1] Anold, J. (2000). Affect in Language Learning. Beijing: Foreign Language Teaching and Research Press, People's Education Press and Cambridge University Press.

[2] Bailey, K.M. (1999). Using learning styles to predict foreign language achievement at college level. System, 28:115-133.

[3] Bem, S. (1974). The measurement of social androgyny. Journal of Consulting and Clinical Psychology, 42:155-162.

[4] Brown, D. (1994). Principles of language learning and teaching (3rdedition) .Englewood Cliffs, NJ: Prentice Hall Regent.

[5] Belenky, M.F., Clinchy, B.M., Goldberge, N.R. \& Tarule,J.M. (1986). Women's ways of knowing: The development of self, voice, and Mind. New York: Basic Books.

[6] Chipman,S. (1988). Far too sexy a topic: Review of J. Hyde and M.C. Linn (eds.), The Psychology of Gender: Advances Through Meta-Analysis. Educational Researcher, 17(3):46-49.

[7] Nunan, D. (2002) Second Language Teaching and learning. Beijing: Foreign Language Teaching and Research Press.

[8] Day, R. (1984). Student's participation in the ESL classroom or some imperfections in practice. Language Learning, 34(3): 69-102.

[9] Dixon, N. M. (1985). The implementation of learning style information . Lifelong Learning, 9(3):16-18, 26-27.

[10] Dreyer, C. (1998). Teacher-student style wars in South Africa: the silent war. System 26(1), 115-126.

[11] Dunn, R. \& Dunn, K. (1978). Teaching students through their individual learning styles: A practical approach. Englewood Cliffs, NJ: Prentice-Hall.

[12] Ellis, R. (1994). The study of second language acquisition. Oxford: Oxford Press.

[13] Gregorc, A.F. 1979. Learning/teaching styles: Potent forces behind them. Educational leadership 36: 236-238.

[14] Ding Yeren, (2004). The Study of Second Language Acquisition. Shanghai: Shanghai Foreign Language Education Press.

[15] Keefe, J.W. (1979). Leaning style: An overview. In J. W. Keefe (ed.), Student learning styles: Diagosing and prescribing programs. Reston, VA: National Association of Second School Principals.

[16] Kinsella, K. (1994). Perceptual Learning Styles Survey. Paper presented at the International TESOL Convention.

[17] Liu Ruiqing \& Dai Manchun, (2001). Report on the Learning Styles of EFL Learners in China. Beijing: Foreign Language Teaching and Research Press

[18] Oxford, R.L., Lavine, R.Z., \& Crookall, D. (1989). Language learning strategies, the communicative approach, and their classroom implications. Foreign language Annals, 22(1): 29-39.

[19] Oxford, R.L. (1990). Language learning strategies and beyond: A look at strategies in the context of styles. In S.S. Magan (Ed.), Shifting the instructional focus to the learner. Middlebury, VT: Northeast Conference on the Teaching of Foreign Languages, 35-55.

[20] Reid. J (2002). Learning styles in the ESL/EFL Classroom. Beijing: Foreign Language Teaching and Research Press.

[21] Reid. J (1987). The learning style preferences of ESL students. TESOL Quarterly 21 (1):87-117.

[22] Rossi-Le, L. (1989). Perceptual learning style preferences and their relationship to language learning strategies in adult students of English as a second language. Iowa: Drake University, Des Moines.

[23] Schmeck, R. R. (1983). Learning styles of college students: Individual differences in Cognition. New York: Academic Press.

[24] Scarcella, R. (1990). Teaching language minority students in the multicultural classroom. Englewood Cliffs, NJ: Prentice-Hall/Regents.

[25] Chuming Wang, (1992). Learning Psychology in Chinese EFL Learners, Changsha: Hunan Education Press.

Feng Liu, (Tujia Zu) 31, is a lecturer teaching English language in English department of Sichuan Agricultural University. He attained his MA degree of Foreign Language and Literature in Southwest Jiaotong University in China. He has interests in foreign language education and second language acquisition. 